Section had received from leading British physiologists. Prof. A. V. Hill spoke of the international character of physiology and of its status as an independent science. If physiology had been content to be merely the handmaid of medicine and to give important positions only to medical men, it would have missed many of its ablest exponents--Pasteur, Langley, Barcroft, Cannon, Bayliss, Lucas, Krogh, Lapicque, and many others, including, we may add, A. V. Hill himself.

\section{Social Mind of the Individual}

K. C. Mukherji took, for the subject of his presidential address to the Section of Psychology, the "Social Mind of the Individual". He regretted that there should be any controversy about the importance of social compared with individual psychology, since it is a matter of observation that individual psychology depends as much upon the psychology of society as the psychology of society upon it.

While admitting the importance of the institution of the family life for the welfare of the State in its material aspects, he emphasized that the mental effects of the family life in relation to the foundations of national sentiment are equally important. Although the effects of family life on one hand may be a barrier to the development of wider social interests, it is, however, the necessary preparation for the foundation of the social sentiments. The views of various writers on the ultimate elements of social interests were critically considered.

Mr. Mukherji thinks that life in the first instance is a social life which grows unconsciously, but, when with advancing individual development the critical spirit arises, the unconscious acceptance of the social group becomes modified by conscious effort; thus the social life may be said to be individualized.

The relation of the individual to the group led him to consider the relationship between minor groups under the political, economic, or cultural dominance of a major group. If the minor group accepts the dominance of the major group, there is no trouble; if the minor group assumes an attitude of equality or superiority in some field, it threatens the prestige of the major group, and fear of that loss tempts to aggression. He thinks that this represents the problem of the Jews in Germany, and the HinduMuslim tension. The address raised some very interesting problems in a clear form.

\title{
X-Ray Studies of Proteins
}

$\mathrm{A}^{\mathrm{T}}$ $T$ the thirty-seventh lecture of the Bedson Club at Armstrong College, Newcastle-on-Tyne, on March 5, Dr. W. T. Astbury gave an account of his work on the "X-Ray Interpretation of Protein Structure".

Proteins can be divided into two classes, fibrous and globular, and they all contain $\alpha$-amino acids condensed, primarily, as polypeptide chains. This classical theory of Emil Fischer does not fully characterize the proteins, and research has shown that these long polypeptide chains are folded and further cross-linked by the reactive centres of the side chains. In dealing with the proteins, it is necessary to ask three questions: What are the side chains? How are they distributed? And what is their stereochemical aspect? Dr. Astbury dealt with the last topic.

The fibrous proteins are mainly stable, the simplest being fibroin (silk protein) which consists largely of glycine and alanine residues. Its X-ray photograph agrees with the view of a fully extended polypeptide chain, and this is confirmed by the fact that silk fibres cannot be reversibly stretched. Any stretching that does occur is permanent and due to the crystallites sliding over one another. The stretching of wool, hair, etc., is about a hundred per cent and reversible, and the usual X-ray photograph is not the same as that of fibroin; but on stretching, a similar photograph has been obtained, indicating that keratin (the protein of hair) is a fully extended polypeptide chain system only in the stretched state ( $\beta$-keratin); the unstretched condition is known as $\alpha$-keratin. It seems, therefore, that in the $\beta$-keratin form the proteins consist of parallel polypeptide chains linked by cross-linkings, while in the normal or $\alpha$-form these chains are folded. If keratin is stretched and steam applied, the cross-links are hydrolysed and the extension then becomes permanent by the formation of new cross-links. Keratin fibres can also be contracted by nearly fifty per cent (supercontraction) due to further folding of the main-chain. This supercontraction of hair has been found to be very similar to the contraction of muscle. The extension and contraction of many fibrous proteins can take place by free rotation around the single valency links, and therefore unreasonable straining of the valency bonds does not occur.

The globular proteins are only stable within narrow limits. Some of them have been obtained in a crystalline state, and in this condition X-ray investigation has been possible. Svedberg, by means of the ultracentrifuge, has indicated that the molecular weight is a simple multiple of 35,000 (approx.). The characteristics of this class are rapidly lost on denaturation, and the stretched state of the denatured protein gives $\mathrm{X}$-ray photographs very like those of $\beta$-keratin and the stretched fibres in general, thus showing that all proteins, whatever they are in the natural state, can be brought to a condition approximating to long polypeptide chains with crosslinks.

The folding of these chains must be specific, and Dr. Astbury discussed possible methods by which this could take place, and indicated how supercontraction was brought about. The specificity argues some controlling factor, and it was suggested that this is a property of the side chains.

In conclusion, Dr. Astbury dealt with the feather protein and the virus which causes 'mosaic' disease in tobacco plants. The former falls between the fibrous and globular, while the latter, analogous in several ways to feather protein, appears to be no other than a crystallizable protein bridging the supposed gap between living and non-living matter. 